\title{
Analysis on the Critical Theory of Everyday Life Proposed by Agnes Heller
}

\author{
Xiaoyu Wang \\ School of Philosophy and Social Development \\ Huaqiao University \\ Xiamen, China
}

\begin{abstract}
Through the phenomenological research methods, Agnes Heller has carried out the study on daily life from various angles, and she is committed to the construction of individual ethics. In her book -- Everyday Life, she pointed out the importance of turning individuals from self-being to self-acting, by transforming the world's daily life and changing the individual attitude, to make the social structure more humanized. And those critiques and efforts Heller has made on daily life are worth our attention and thinking.
\end{abstract}

Keywords-Heller; personality and character; species-nature objectifications

\section{INTRODUCTION}

Agnes Heller is a very famous Eastern European Marxist scholar, and she has a wide range of researching fields, among which daily life is the main theoretical issue concerned by her. Everyday Life published in 1970 is the concentrated reflection of this theory. The theory about daily life has laid the structural foundation of her whole theoretical system. She tried to pay attention to the problem of humanization by exploring the structure of daily life and building up individual ethics, regardless of the economy and class analysis.

\section{THE STUDY ON THE ORIGIN OF HELLER 'S DAILY LIFE THEORY AND ITS SPECIAL HISTORICAL BACKGROUND}

Heller's daily life theory is considered to be derived from the theory of labor alienation by Marx, the critical theory of daily life proposed by Lukács and the theory of trinity put forward by Lefebvre; its unique realistic incentive is that the De-Stalinisation Movement took place in Eastern Europe, so her daily life theory not only has the transforming of daily life in Western Marxism, but also has the special political background of Eastern Europe.

Firstly, the Marxian theory that affected Heller is found in Marx's Economic \& Philosophical Manuscripts in 1844. In the manuscript, Marx pointed that when men's conscious and free objectification activities of species-nature became forced ones, men would not be really humans with actual meanings, but the same as animals. He said in the manuscripts, "As a result, therefore, man (the worker) only feels himself freely active in his animal functions - eating, drinking, procreating, or at most in his dwelling and in dressing-up, etc.; and in his human functions he no longer feels himself to be anything but an animal. What is animal becomes human and what is human becomes animal."1

This view of the alienation of species-nature between men has been greatly reflected in Heller's critical theory of daily life. She believes that the elimination of men's alienation should be started from individuals themselves, and transforming alienated individuals into individuals that have a conscious relationship with species-nature should be started from the micro felid of daily life.

Secondly, the critical theory of daily life proposed by Lukács affected Heller. Lukács agreed in several alienation points of Marx, and he argued that alienation was produced by materialization. He also thought that materialization and alienation existed not only in the field of economic life but also in the field of ideology, and the alienation in the field of ideology was mainly produced by the field of daily life. At the same time, he believed that the sublation of alienation also had to pass two ways: one was from socio-economic aspects, the other is from individuals' daily life. He considered that the sublation of alienation should be obtained by using ideological achievements, which mainly relies on the development of personality to achieve the sublation of materialization in the whole society. However, he didn't agree that this goal could be reached only through individual efforts, so he pinned his hopes on social revolutions. Heller also agrees to sublate alienation, but different from Lukács, Heller attaches more importance on the power of individuals. She believes that the sublation of alienation should start with the most realistic micro field of daily life.

Then, Lefebvre put forward the theory of Trinity. He pointed out that "the process of social development, for philosophical meanings, includes two aspects: the fact of the constant growing of men - and the growing alienation including the capitalist society, where alienation is also comprehensive, and it envelops every part of life."

Lefebvre argued that alienation already existed in all aspects of human life. For he thought alienation had universality and continuity, if alienation was to be sublated, it

\footnotetext{
${ }^{1}$ Karl Heinrich Marx. 2000. "Marx's Economic \& Philosophical Manuscripts in 1844" [M]. Offprinted by Renmin Publishing House, Beijing. p55

${ }^{2}$ Chen Xueming, Wu Song, Far East Makes Daily Life Become Artwork On Daily Life by Lefebvre, Heller [M]. Kunming, Yunnan People's Publishing House, 1998, p1.
} 
should be done by an overall revolution. The revolution should be of trinity, and also should be carried out from three aspects including economy, politics, culture. Heller has also carried out a deep analysis on the important role that daily life played on the development process of the whole society. She argues that revolutions and reforms of daily life, compared to macro revolutions, are more important, and she proposes an approach to the humanization of daily life.

Heller's thoughts have realistic incentives and an international social background. Her father was persecuted by fascists and killed in Auschwitz concentration camp before the end of World War II, which raised her thoughts about the whole human society. Therefore, she began to study social life and daily life. During the Czechoslovak incident in 1968, she started to think about the possibility of a non-political revolution, after she saw the negative effects on the society caused by armed struggle and bloody sacrifices. Thus, she put forward the micro revolution route to start with changing people's attitude from daily life.

\section{THE ANALYSIS AND RESEARCH ON THE BOOK EVERYDAY LIFE}

When facing the objective world, men as individuals will have different reactions, so that they will have different meanings to themselves and the society. According to that, Heller divided individuals in daily life into individuals with "character" and individuals with "personality".

Firstly, personality and character. A character is an attribute of an individual, which may lead to exclusionism emotions and alienation. The root of the character is that everyone is a special and unique existence. However, Heller thinks that the character does not necessarily lead to exclusionism. Although people are born in the society already existed, some habits and customs of the society are naturally exclusive. However, whether an individual is an exclusive one does not depend on whether he has a character, but depends on the position of the character in his life, which is his attitude towards the character. Heller believes that characters are unavoidable, but if people know when to terminate those characters in daily life, they are not merely individuals with characters but become individuals with personality.

Personality is an attribute related to the free and conscious species-nature, and an existence mutually united with individual character in an individual. Marx thought, "In creating a world of objects by his personal activity, in his work upon inorganic nature, man proves himself a conscious species-being, i.e., as a being that treats the species as his own essential being, or that treats itself as a species-being."3

Heller believes that a man with his personality as the upper hand is a man who understands himself as a species-being, and understand his own species-nature. This kind of men will consciously realize that the essence of life is the object of men, and that men should actively create and transform their life rather than lose their self-conscious initiative. On the contrary, alienated men are no longer the free and self-conscious

${ }^{3}$ Karl Heinrich Marx. 2000. "Marx's Economic \& Philosophical Manuscripts in 1844" [M]. Offprinted by Renmin Publishing House, Beijing. p7. subjects but only the carriers with demands. The difference between a man with personality and an alienated man is that a man with personality can give full play to his subjective initiative and constantly transform the objective world and create a new objective world, even if he is born in an alienated society. Heller thinks that the cultivation of individual personality is an important task of daily life.

Zhu Zhoubin thinks that Heller's "typical individual" concept can be simplified to correspond to intellectuals, while the subject of "characters" can be specific to ordinary people. There are significant differences between intellectuals' and ordinary people's ways of daily life. The former is in the forefront of the latter, so the latter gets into a contradiction; the purpose of the former only can be truly achieved by the reaction of the latter. ${ }^{4}$

\section{EMPHASIS ON THE MAIN IDEA OF HELLER'S DAILY LIFE CRITIQUE}

Heller has proposed that the self-being and self-acting of species-nature separately point to the existing daily living world and the ideal daily living world.

First, the species-nature objectification of self-being. For men, the Society is "self-being existence", i.e., the premise and foundation of existence, while the species-nature activities of self-being include three fundamental elements -- tools, habits and languages. The species-nature objectification of self-being will provide rules for the behaviors of the activities. The rules do not transcendentally exist in everyone's mode of thinking. Those rules get internalized through repeated practicing, and are used for the species-nature objectification of descendants.

Second, the species-nature objectification of self-acting. The species-nature objectification of self-acting points to human's free and conscious transformation of the world. In this kind of the species-nature objectification, men can freely and consciously choose their own way of activities and are not controlled by the most basic physiological needs. This kind of objectification is guided and dominated by men's conscious intention. Its production and development have their own special laws and methods, relying on the economic foundation and reflecting its level from another side.

The transforming from self-being to self-acting shows the individual freedom based on self-being. However, Heller does not consider that self-being and self-acting exist independently, corresponding to alienation and non-alienation respectively. She believes that the self-being of daily life is of a tendency, and the consciousness of "for our existence" in the sphere of self-being will continue to be produced, and those two cannot be separated into two spheres, self-being and self-acting.

However, on the one hand, we have learned the study of Heller's species-nature objectification theory. On the other hand, Zhao Sikong has also pointed out that Everyday Life is only the starting point of Heller's theory about daily life, and there is still more abundant content in her later works. It is because of this that Heller's theory of daily life can take a place

\footnotetext{
4 Zhu Zhoubin.2011. "Heller's Basic Value on Everyday Life \& Its Revelation” [J]. Sanxia BBS, 2011, (2) : 106.
} 
in the 21st century's Marxism. The spheres borrowed from Lukács and Hegel, such as "self-being, self-acting" and "species-nature", already disappeared when Heller extended the theory of daily life to the level of moral ethics, and she began to focus on the construction of individual ethics. Similarly, Yan Yan also believes that Heller did not elaborate on the relations between the macro-scale economic \& political changes and the humanization of daily life, but consciously expanded her early narrow theoretical perspective in the later theoretical construction, and put daily life into modern criticism, moral philosophy and aesthetics for comprehensive studies.

\section{THE REFERENCING VALUE OF HELLER'S DAILY LIFE CRITIQUE ON THE LOCALIZATION OF MARXISM IN CHINA}

Marxist philosophy is a high level of summary about the laws of the society and history, and it is also a theory that guides the proletariat and all humans to liberation. As a scientific theory, Marxism has great guiding significance to practicing. For the combination of theory and practice is not a combination of seeking truth from facts, Marxism is not a very good solution to people's lives. Therefore, the localization of Marxism in China is not only a matter in non-daily life sphere, but its implementation and progress are closely related to the life of people. Thus, we should pay attention to the Heller's daily life critique, and start from the critique in daily life, to set up a foundation for the realization of human liberation.

\section{CONCLUSION}

The critical theory of daily life is a serious theoretical problem. Researching on it aims to draw on its rationality, and its irrational part should be criticized and sublated, which will guide the practicing in daily life, to promote people's life towards an increasingly "humane" direction, and to make the whole society into a more stable and sustained development. We can see Heller's research ideas to supplement the studying methods of Marxism from a micro perspective; we see the meaning of daily life critical theory to analyze the status of daily life and put forward solving measures. At the same time, we can also see something in Heller's critical theory of daily life needs improvement: she neglects the importance of objective environmental changes while emphasizing the initiative of individuals. To change the society fundamentally, we still need the power of materials to promote the process and carry out thorough political revolutions, although the power of individuals cannot be ignored.

\section{REFERENCES}

[1] Chen Xueming, etc.1998. "Changing Daily Life into Artwork" [M]. Yunnan people's Publishing House.

[2] Agnes Heller.2010. "Everyday Life" Translated by Yi Junqing [M]. Heilongjiang University Press.

[3] Karl Heinrich Marx.2000. "Marx's Economic \& Philosophical Manuscripts in 1844" [M]. Offprinted by Beijing Renmin Publishing House.

[4] Yang Mingyue.2014. "Study on Agnes Heller's Alienation and Critical Theory of Everyday Life" [D]. Nanjing Normal University Press.
[5] Du Hongyan.2009. "Walking to the Humanization of Daily Life" [D]. Heilongjiang University Press.

[6] Zhu Zhoubin.2011. "Heller's Basic Value on Everyday Life \& Its Revelation" [J]. Sanxia BBS (Theory Edition of Sanxia Literature).

[7] Li Xiang.2012. "Study on Heller's Critical Theory of Everyday Life" [D]. Heilongjiang University Press.

[8] Wang Jing.2011. "Heller's Theory of Individual Liberation \& Its Revelation" [J]. Seeking Truth.

[9] Wei Yaran.2014. "Study on Heller's Critical Theory of Everyday Life" [D]. Shanxi University Press.

[10] Yan Yan.2009. "Explore the Way of the Humanization of Daily Life Reviews on Agnes Heller's Critical Theory of Daily Life" [J]. Chinese and Foreign Cultural and Literary Theory.

[11] Zhao Sikong.2013. "Foreign Marxism's Daily Life Transformation \& Its Revelation - Taking the Example of the Critical Theory of Lukács, Gramsci and Heller" [J]. Philosophy Analysis. 